\title{
12-PULSE LCI SYNCHRONOUS DRIVE FOR A 20 MW COMPRESSOR MODELING, SIMULATION AND MEASUREMENTS
}

\author{
J.-J. Simond Member IEEE, A. Sapin Member IEEE, M. Tu Xuan, R. Wetter, P. Burmeister Member IEEE \\ Ecole Polytechnique Fédérale de Lausanne (EPFL) \\ Laboratoire de Machines Electriques \\ $\mathrm{CH}-1015$ Ecublens, Switzerland \\ Tél. : +41 2169348 04, Fax : +41216932687 \\ Email : jean-jacques.simond@epfl.ch
}

\begin{abstract}
The current source thyristor inverter is still today a suitable choice for supplying high power adjustable speed drives for pumps or compressors. This paper presents a 12-pulse LCI (load commutated inverter) synchronous drive for a $20 \mathrm{MW}$ compressor, it focuses on the following main aspects: modeling of the complete drive system, numerical simulation and comparison between calculated and measured values of the pulsating torque components in steady-state operations. The modeling of the sixphase synchronous motor is obtained by using a new virtual testplatform for large electrical machines. The pulsating torque components are measured in real time with a digital transient torque measurement device.
\end{abstract}

Index terms - modeling, simulation, test, adjustable speed drive

\section{INTRODUCTION}

The basic configuration of the investigated and measured drive system is given in Fig. 1.

The 12-pulse line side rectifier is supplied with a three windings transformer (vector group Dd0y1) in order to eliminate the $5^{\text {th }}$ and the $7^{\text {th }}$ harmonics in the line current. This converter is line commutated.

The 12-pulse machine-side inverter supplies the two threephase stator windings of the high speed synchronous motor. This converter is load commutated and operates at variable voltage and frequency which depends on the motor speed.

The inductances in the d.c. circuits decouple both converters and smooth the d.c. current.

The synchronous motor is of type solid iron cylindrical rotor with a complete damper winding made of the highly conductive slot wedges of the excitation slots. The two stator windings are displaced by $30^{\circ}$ in order to eliminate the $5^{\text {th }}$ and the $7^{\text {th }}$ harmonics in the resultant air gap field and consequently the $6^{\text {th }}$ rotor currents harmonics as well as the pulsating-torque component of the $6^{\text {th }}$ order. The synchronous motor modeling and the predetermination of its equivalent circuit diagrams are described in section 3 .

The excitation system of the synchronous motor is supplied with a rotating field exciter combined with a rotating diode rectifier.

The control and protection devices are represented as a macro in Fig. 1. They will not be described in detail because the comparisons measurements - simulations presented in this paper concern steady-state operations characterized by constant firing angles for each converter. Principally, the motor operates at rated flux under nominal speed. A speed regulator generates a d.c. current set value in order to produce the required torque to reach the reference speed. The current regulator output acts on the firing angle of the line-side converter.

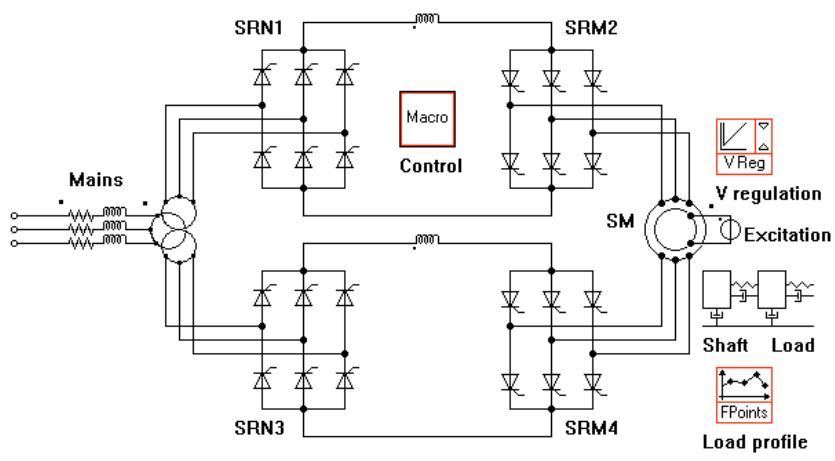

Fig.1: 12-pulse LCI fed synchronous motor

(20 MW, 2x3800 V, 70,6 Hz, 4236 rpm) 


\section{PULSATING TORQUE COMPONENTS}

For such a drive system, it is extremely important to evaluate in advance the frequencies and the amplitudes of the pulsating torque components in order to avoid resonance with the mechanical shaft. The pulsating torque components are due to the current harmonics which are impressed on the motor by the converters. These pulsating torque components can be classified as follows $\left(f_{M}=\right.$ motor frequency; $f_{N}=$ network frequency):

- integer pulsating torques with the frequencies $\mathrm{k} . \mathrm{f}_{\mathrm{M}}$ :

$\mathrm{k}=6,12,18,24, \ldots(\mathrm{LCI}-6)$, or $\mathrm{k}=12,24, \ldots(\mathrm{LCI}-12)$.

- non-integer pulsating torques with the frequencies k. $\mathrm{f}_{\mathrm{N}}$ :

$\mathrm{k}=6,12,18,24, \ldots$ (LCI-6), or $\mathrm{k}=12,24, \ldots$ (LCI-12).

- non-integer pulsating torques depending on both the network

frequency and the motor frequency according to:

$\mathrm{f}=\left|\mathrm{k} \cdot \mathrm{f}_{\mathrm{n}} \pm \mathrm{n} \cdot \mathrm{f}_{\mathrm{M}}\right| \cdot \mathrm{k}$ and $\mathrm{n}$ defined as $\mathrm{k}$ above.

The non-integer pulsating torque components do not exist if the current through the intermediate dc-circuit is perfectly smoothed.

The numerical evaluation of these pulsating-torque components and the comparison with their directly measured values are the central aspects of this paper.

\section{SYNCHRONOUS MOTOR MODELING}

The analysis of large synchronous machines behavior in steady state or transient conditions requires a precise modeling, in other words an accurate knowledge of the equivalent circuit diagram parameters and/or of the characteristic quantities of the machine. These characteristic quantities can be determined either analytically $[1,2]$ or experimentally by different tests, i.e. the no-load sudden three phase short-circuit [3]. These tests, however, require an important and expensive equipment. They are not devoid of any risk and cannot be performed up to the material limits.

The basic idea proposed here to obtain the complete set of characteristic quantities is to replace the traditional testplatform of the manufacturer by a virtual one [4,5], whose basic structure is represented in Fig. 2. This virtual test-platform allows in particular the following tests: short-circuit tests at noload in the d-axis or under load conditions in the q-axis, standstill tests in both axes with variable frequency up to twice the rated frequency, DC-decay tests. Results obtained on the traditional and on the virtual test-platform for different large synchronous machines (salient pole machines and turbogenerators) are compared in [5], they are extremely close.

For a given test, the use of the virtual test platform involves three stages.

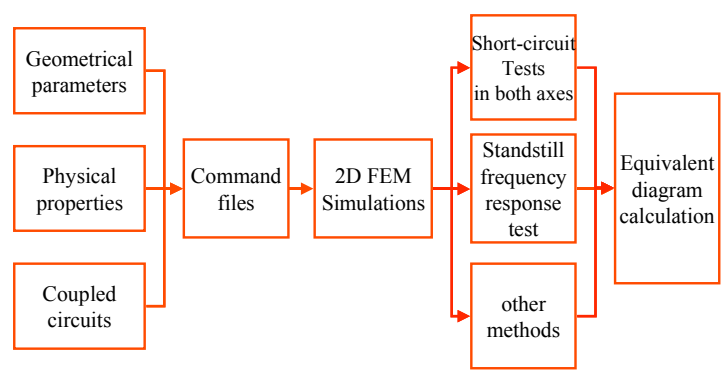

Fig. 2: Basic structure of the virtual test platform.

The first stage is a pre-processing, which consists in preparing data for the FEM calculations. Based on the detailed knowledge of the geometry and physical properties of the machine electrical and magnetic circuits, command files are generated (Fig. 2).
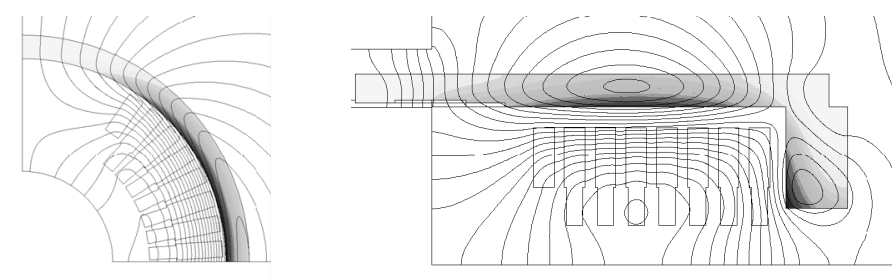

Fig. 3: Field end-winding leakage flux

In a second stage, 2D-FEM transient field calculations corresponding to the different tests offered are performed using Flux 2D [6]. The question: "would it be more judicious to use a 3D field calculations tool ?" is justified. With respect to the required calculation time on the best available $\mathrm{PC}$, in the case of a sudden no-load short-circuit, the response to this question is clearly no, at least for industrial applications. Therefore, Flux 2D is suitable for this kind of investigations. It takes into account saturation and eddy current effects, and also offers a lot of useful features like partial automatic mesh generation, sliding air gap band for rotation calculations, or external coupled circuits. This latter feature is particularly precious because a 2D FEM calculation does not take into account the stator and rotor end-winding leakages. Therefore, these endwinding leakages have to be determined through additional 2DFEM calculations, as shown for example in Fig. 3 for the endwinding leakage of the excitation circuit. In others words the proposed method corresponds to a " $2.5 \mathrm{D}$ field calculations method", this is a attempt to get simultaneously a good precision and acceptable calculation times.

The third stage concerns the analysis of the FEM calculations results; this leads to the characteristic quantities and to the equivalent circuits in both axes of the machine. 
Finally, it is possible to check the results accuracy through a backwards digital simulation of the same test using the equivalent circuits obtained with the virtual test-platform.

Fig. 5 and Fig. 6 show the stator and the field currents during a no-load test under nominal voltage of a 200 MVA air cooled turbo-generator performed on the virtual test platform.

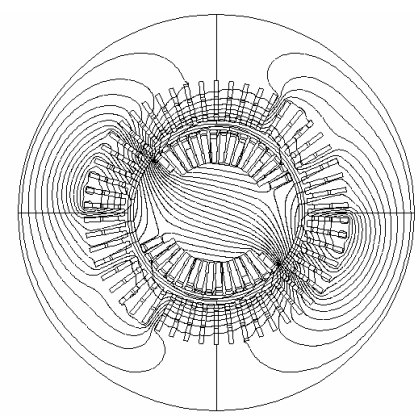

Fig. 4: Field distribution some ms after a no-load short-circuit test.

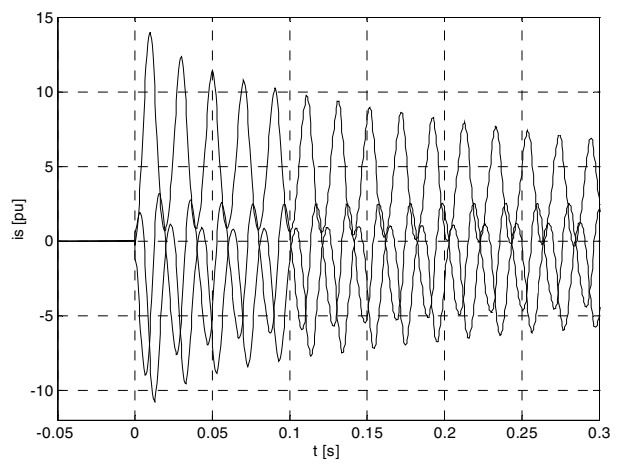

Fig 5: Stator currents after a no-load short-circuit test.

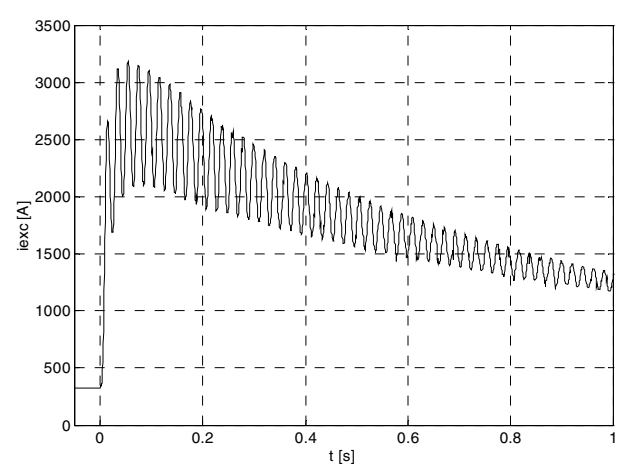

Fig. 6: Field current after a no-load short-circuit test.

Practically, two tests have to be performed on the virtual platform in order to get all the characteristic quantities and equivalent circuit diagrams in both axes of a given machine.
The first one is a no-load sudden short-circuit test with an initial voltage $\mathrm{u}_{0}$ (test in the d-axis, Fig. 5 and 6), the second one is a short-circuit test under load condition at $\cos \varphi=0$ and $u=u_{\text {load }}$ (test in the q-axis). $\mathrm{u}_{0}$ and $\mathrm{u}_{\text {load }}$ are chosen so as to get shortcircuit currents leading to saturation levels of the different leakage paths corresponding to those expected during the numerical simulations to be performed later using the equivalent circuits obtained through these two tests, i.e. shortcircuits under load conditions, out of phase synchronizing, fault clearing, ...

Basically all the necessary information for determining the characteristic quantities and the equivalent circuits in both axes is contained in the decrease versus time of the stator current vector obtained after filtering the non-periodic components in each phase, as well as in the decrease of the field current after the no-load test.

On this way, it becomes possible to take properly into account the rotor construction and especially the massive iron parts through sub-subtransient reactances and time constants.

Due to the fact that the virtual test-platform has been built for three-phase machines, its use for a six-phase motor requires a preliminary step with both stator windings connected in series.

The use of the virtual test-platform for the investigated sixphase synchronous motor with both stator windings connected in series leads to the following results (equivalent 3-phase motor modeling with 3 rotor circuits in the d-axis and 2 or 3 in the q-axis, in that case 2 q-axis circuits, table 1). Afterwards the equivalent circuits of the six-phase motor can be obtained as represented in Fig. 7. For this transition the stator winding pitch has to be taken into account in order to precisely get the mutual leakage reactance $\mathrm{x}_{\sigma \mathrm{s} 12}$ between both stator windings.
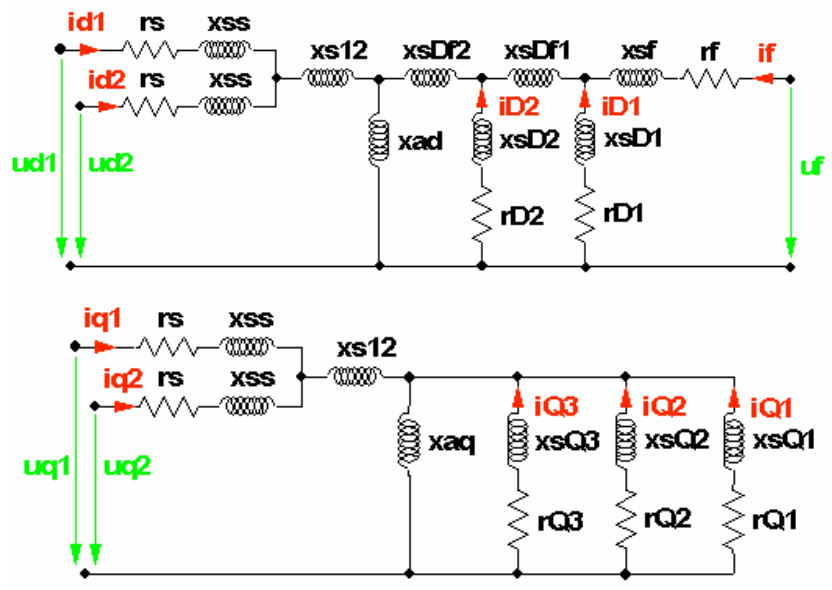

Fig. 7: d- and q-equivalent circuits of the 6-phase synchronous motor.

$\mathrm{x}_{\mathrm{d}}=2,161 \quad \mathrm{x}_{\mathrm{d}}{ }^{\prime}=0,3045 \quad \mathrm{x}_{\mathrm{d}}{ }^{\prime}{ }^{\prime}=0,171 \quad \mathrm{x}_{\mathrm{d}}{ }^{\prime}{ }^{\prime}{ }^{\prime}=0,143$ 


$$
\begin{array}{lll}
\mathrm{T}_{\mathrm{d}}{ }^{\prime}=0,6175 & \mathrm{~T}_{\mathrm{d}}{ }^{\prime}=0,081 \quad \mathrm{~T}_{\mathrm{d}}{ }^{\prime \prime}=0,031 \\
\mathrm{x}_{\mathrm{q}}=2,158 \quad \mathrm{x}_{\mathrm{q}}{ }^{\prime}=0,2076 & \mathrm{x}_{\mathrm{q}}{ }^{\prime}{ }^{\prime}=0,1698 & \\
\mathrm{~T}_{\mathrm{q}}{ }^{\prime}=0,098 & \mathrm{~T}_{\mathrm{q}}{ }^{\prime}=0,014 &
\end{array}
$$

Table 1: Characteristic quantities of the equivalent 3-phase motor, reactances in [pu], time constants in [s].

\section{NUMERICAL SIMULATION OF THE DRIVE SYSTEM}

The drive system illustrated in Fig 1 has been simulated using "SIMSEN", a numerical software simulation package for the analysis of power systems and adjustable speed drives developed at the Laboratory of Electrical Machines of the EPFL since more than 10 years. SIMSEN is based on a modular structure and allows the numerical simulation of the behavior in transient and steady-state conditions of power networks and adjustable speed drives having an arbitrary topology [7]. The user builds a topology directly on the screen by choosing and connecting the required modules, afterwards he has to set the parameters of the different modules and to define the operation mode (transient or steady-state conditions). Nowadays SIMSEN offers more than 100 modules, its open structure allows a very easy implementation of new modules. Input- and outputinterfaces facilitate the user's work. For more information, one can refer to: http//simsen.epfl.ch.

\section{REAL TIME MEASUREMENT OF THE AIR-GAP} TORQUE

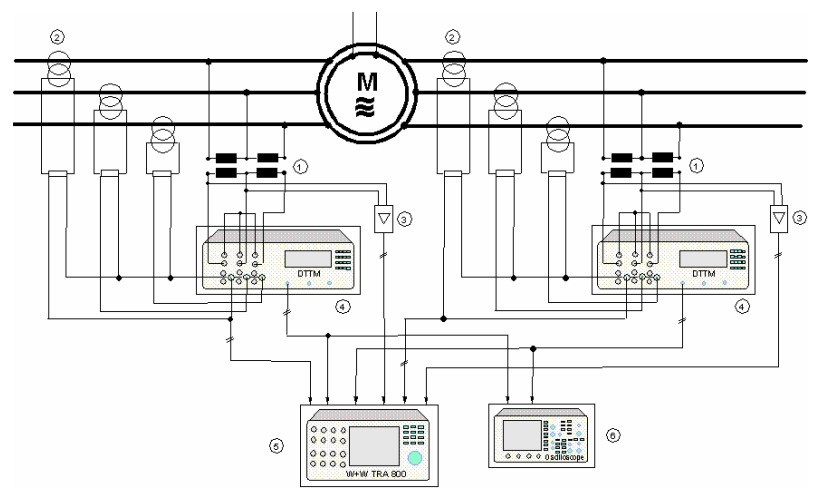

Fig. 8: Measurement arrangement.

The air-gap torque of the tested synchronous motor has been measured by using a digital transient torque measuring device [8] able to make a real time calculation in steady-state or transient conditions of a single or multiphase AC rotating or linear machine supplied with sinusoidal voltages or through frequency converters with commutation frequencies up to $30 \mathrm{KHz}$. This device needs no shaft position or speed sensors, it exclusively uses the acquisition of the stator currents and voltages, therefore the torque measurement is completely independent of the machine size and ratings.

In the case of a six phase synchronous motor, two torque meters are required for the air gap torque measurement as shown in Fig. 8. The resulting air-gap torque is the sum of the torque contributions brought by each stator winding.

\section{COMPARISON MEASUREMENT - SIMULATION}

Fig. 9 shows the comparison between measurement and simulation results. The measurement results were obtained on the test-shop of the motor manufacturer by running at an operation point at reduced active power $(2,94 \mathrm{MW} ; 4236 \mathrm{rpm} ; 2$ x $3800 \mathrm{~V} ; \cos \varphi=0,91$.

The good visual concordance between measured and simulated curves in Fig. 9 is confirmed by considering the Fourier analysis of torques $\mathrm{T}_{1}\left(\right.$ or $\left.\mathrm{T}_{2}\right)$ and $\mathrm{T}_{1+2}$ given in Table 2 , which gives all pulsating torque components exceeding $2 \%$ of the torque mean values (3240 respectively $6480 \mathrm{Nm}$ ).

\begin{tabular}{|l|l|l|l|l|}
\hline \multicolumn{1}{|c|}{$v$} & \multicolumn{1}{|c|}{$\mathbf{f}(\mathbf{H z})$} & $\begin{array}{c}\text { test } \\
(\mathbf{N m})\end{array}$ & \multicolumn{1}{|c|}{$\begin{array}{c}\text { simulation } \\
(\mathbf{N m})\end{array}$} & $\begin{array}{c}\text { difference } \\
(\%)\end{array}$ \\
\hline $\mathbf{6 . f _ { \mathbf { M } }}$ & $\mathbf{4 2 3 , 6}$ & $\mathbf{6 1 4 , 3}$ & $\mathbf{6 2 9 , 3}$ & $\mathbf{2 , 4}$ \\
\hline $\mathbf{1 2 . f _ { \mathbf { M } }}$ & $\mathbf{8 4 7 , 2}$ & $\mathbf{2 2 7 , 1}$ & $\mathbf{2 3 0 , 5}$ & $\mathbf{1 , 5}$ \\
\hline $\mathbf{1 8 . f _ { \mathbf { M } }}$ & $\mathbf{1 2 7 0 , 8}$ & $\mathbf{1 4 0 , 9}$ & $\mathbf{1 4 2 , 8}$ & $\mathbf{1 , 3}$ \\
\hline $\mathbf{2 4 . f _ { \mathbf { M } }}$ & $\mathbf{1 6 9 4 , 4}$ & $\mathbf{9 7 , 3}$ & $\mathbf{1 1 0 , 1}$ & $\mathbf{1 3 , 0}$ \\
\hline $\mathbf{3 0 . f _ { \mathbf { M } }}$ & $\mathbf{2 1 1 8 , 0}$ & $\mathbf{7 8 , 5}$ & $\mathbf{7 7 , 0}$ & $\mathbf{- 2 , 0}$ \\
\hline $6 . f_{\mathrm{N}}$ & 300,0 & 755,8 & 779,2 & 3,1 \\
\hline $12 . \mathrm{f}_{\mathrm{N}}$ & 600,0 & 137,9 & 155,5 & 13,0 \\
\hline
\end{tabular}

Fourier analysis torques $T_{1}$ or $T_{2}$; mean values $3240 \mathrm{Nm}$

\begin{tabular}{|l|l|l|l|l|}
\hline \multicolumn{1}{|c|}{$v$} & \multicolumn{1}{|c|}{$\mathbf{f}(\mathbf{H z})$} & $\begin{array}{c}\text { test } \\
(\mathbf{N m})\end{array}$ & \multicolumn{1}{|c|}{$\begin{array}{c}\text { simulation } \\
(\mathbf{N m})\end{array}$} & $\begin{array}{c}\text { difference } \\
(\%)\end{array}$ \\
\hline $\mathbf{1 2 . \mathbf { f } _ { \mathrm { M } }}$ & $\mathbf{8 4 7 , 2}$ & $\mathbf{4 4 7 , 3}$ & $\mathbf{4 6 0 , 9}$ & $\mathbf{3 , 0}$ \\
\hline $\mathbf{2 4 . f _ { \mathrm { M } }}$ & $\mathbf{1 6 9 4 , 4}$ & $\mathbf{1 9 3 , 8}$ & $\mathbf{2 2 0 , 0}$ & $\mathbf{1 3 , 5}$ \\
\hline $\mathbf{1 2 . f _ { \mathrm { N } }}$ & $\mathbf{6 0 0}$ & $\mathbf{2 7 8 , 6}$ & $\mathbf{3 1 3 , 3}$ & $\mathbf{1 2 , 0}$ \\
\hline $6 . \mathrm{f}_{\mathrm{M}}-6 . \mathrm{f}_{\mathrm{N}}$ & 123,6 & 177,0 & 162,3 & $-8,3$ \\
\hline $12 \mathrm{f}_{\mathrm{M}}+12 \mathrm{f}_{\mathrm{N}}$ & 723,6 & 121,3 & $155,5121,9$ & 0,5 \\
\hline
\end{tabular}

Fourier analysis total torque $\mathrm{T}_{1+2}$; mean value $6480 \mathrm{Nm}$

Table 2: Fourier analysis of the torques $\mathrm{T}_{1 \text { or } 2}$ and $\mathrm{T}_{1+2}$ 

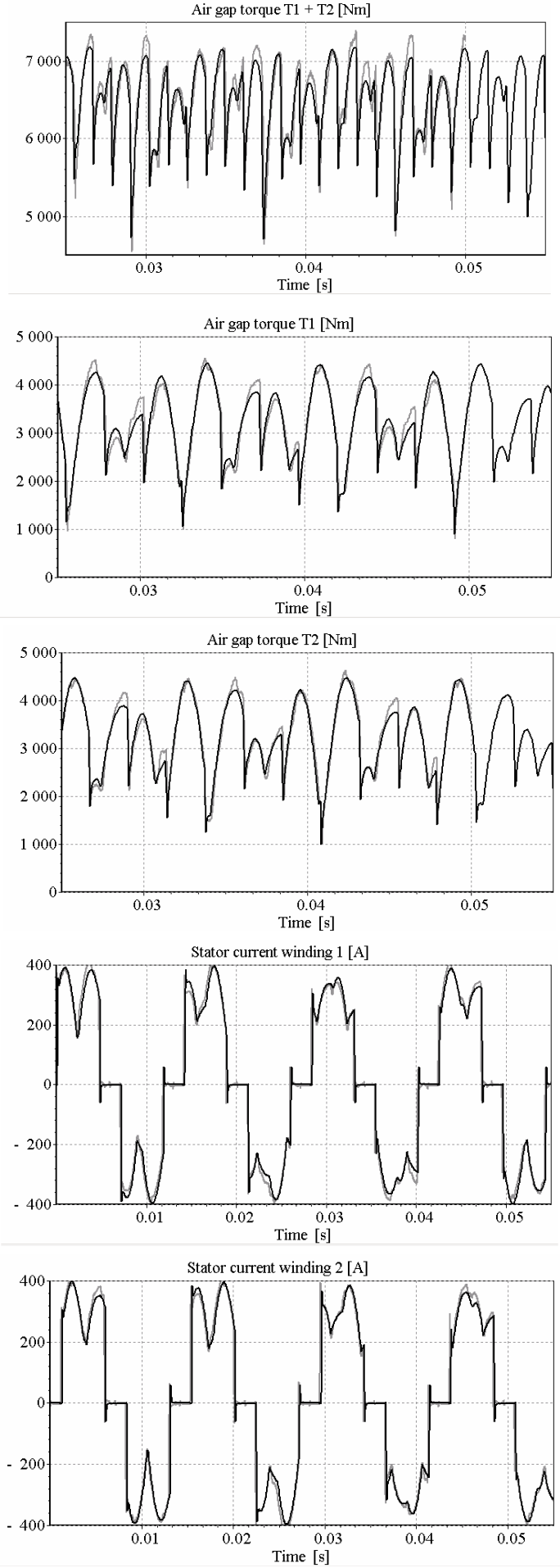

Fig. 9: Comparison measurement (light color) - simulation (dark color); 2,94 MW; $4236 \mathrm{rpm} ; 2 \times 3800 \mathrm{~V} ; \cos \varphi=0,91$

Fig. 9 and Table 2 show a good concordance between measurement and simulation results also for non-integer torque components depending on both network and motor frequencies.
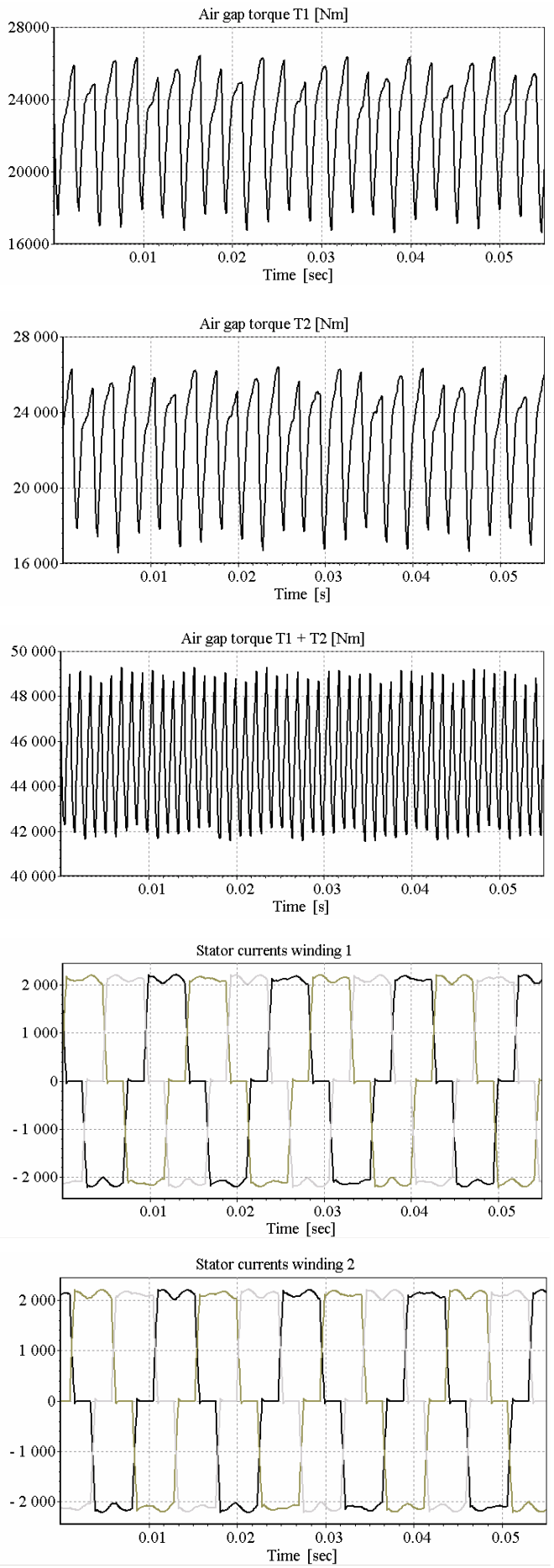

Fig. 10: Simulation at nominal load: $20 \mathrm{MW} ; 4236 \mathrm{rpm} ; 2 \times 3800 \mathrm{~V} ; \cos \varphi 0,91$

Fig. 10 gives the simulation results at nominal load conditions ( $20 \mathrm{MW} ; 4236 \mathrm{rpm} ; 2 \times 3800 \mathrm{~V}$; $\cos \varphi=0,91)$. A comparison 
between Tables 2 and 3 confirms that the non-integer pulsating torque components nearly disappear under nominal load conditions.

\begin{tabular}{|c|c|c|}
\hline & $\mathbf{T}_{1}$ or $\mathbf{T}_{2}$ & $\mathbf{T}_{1+2}$ \\
\hline $\begin{array}{l}\text { Torque mean value } \\
\text { (reference) }\end{array}$ & \multicolumn{2}{|c|}{$45086 \mathrm{Nm}=1 \mathrm{pu}$} \\
\hline v & \multicolumn{2}{|c|}{$\begin{array}{l}\text { Pulsating torques } \\
\text { (pu) }\end{array}$} \\
\hline 6 & 0.075 & - \\
\hline 12 & 0.034 & 0.069 \\
\hline 18 & 0.0093 & - \\
\hline 24 & 0.003 & 0.0061 \\
\hline 30 & 0.0018 & - \\
\hline $6 . \mathrm{F}_{\mathrm{N}}$ & 0.015 & - \\
\hline $12 . \mathrm{F}_{\mathrm{N}}$ & 0.0021 & 0.0042 \\
\hline $18 . \mathrm{F}_{\mathrm{N}}$ & 0.00048 & - \\
\hline 24. $\mathrm{F}_{\mathrm{N}}$ & 0.00019 & 0.00037 \\
\hline $6 . \mathrm{F}_{\mathrm{N}}-6 . \mathrm{F}_{\mathrm{M}}$ & 0.0023 & 0.0045 \\
\hline $12 . F_{N}-12 . F_{M}$ & 0.0002 & 0.00046 \\
\hline
\end{tabular}

Table 3: Fourier analysis torques $T_{1}$ or $T_{2}$ and $T_{1+2}$

\section{CONCLUSION}

A 20 MW LCI-12 supplied synchronous motor has been described, modelized and tested on the test-shop of the manufacturer. The test, performed at partial load conditions, was successful and led to results very close to those of the previous numerical simulation. This good concordance between measurement and simulation results speaks probably for the quality of the measurement equipment and of the used simulation tool. In other words, and in a practical point of view, such a large drive system can be optimally designed only by using suitable simulation tools and rigorously tested if a high performance measurement equipment is available.

\section{APPENDIX}

$\begin{array}{ll}\text { f } & \text { frequency [Hz] } \\ \text { i } & \text { current [p.u.] } \\ \text { r } & \text { resistance [p.u.] } \\ \text { u } & \text { voltage [p.u.] } \\ \text { X } & \text { reactance [p.u.] } \\ \text { T } & \text { time constant [s] }\end{array}$

$\mathrm{T}_{1} \quad$ air gap torque winding $1[\mathrm{Nm}]$

$\mathrm{T}_{2}$ air gap torque winding $2[\mathrm{Nm}]$

$\mathrm{T}_{1+2} \quad$ total air gap torque $[\mathrm{Nm}]$

Indexes

a main field

d,q d-axis, q-axis

D1,D2 damper windings d-axis

F excitation circuit

$\mathrm{k}, \mathrm{v} \quad$ order of harmonics

M motor

$\mathrm{N}$ network

Q1-Q3 damper windings q-axis

S stator

1,2 stator windings

$\sigma \quad$ leakage

\section{REFERENCES}

[1] I.M. Canay: Physical significance of sub-subtransient quantities in dynamic behaviour of synchronous machines; IEE Proc., Pt.B, Vol 135 (1988) 6, pp.334 - 340.

[2] I.M. Canay: Modeling of Alternating-Current Machines Having Multiple Rotor Circuits; IEEE Trans. EC, June 1993

[3] Methods for determining synchronous machine quantities from tests; IEC Standards 34-4 Rotating Electrical Machines. Part 4. 1985.

[4] C. Ramirez: Plate-forme numérique d'essais pour machines électriques de puissance, Thèse EPFL $n^{0}$ 2821, (2003), Lausanne, Switzerland.

[5] C. Ramirez, M. Tu Xuan, J.-J. Simond, D. Schafer, C.-E. Stephan: Synchronous machines parameters determination using finite element method, ICEM 2000 Helsinki, pp. $1130-$ 1133 .

[6] FLUX2D, CEDRAT, France, 1998.

[7] J.-J. Simond, A. Sapin, B. Kawkabani, D. Scahfer, M. Tu Xuan, B. Willy: Optimized design of variable speed drives based on numerical simulation; EPE'97, Trondheim, Norway.

[8] M.T. Nguyen, M. Tu Xuan, J.-J. Simond : Digital transient torque measurement for electrical machines (real time measurement), EPE chapter 1994, Lausanne, Switzerland.

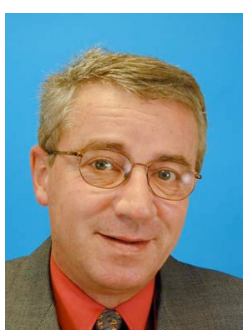

Jean-Jacques Simond received his master degree in 1967 and his Ph.D. degree in 1976 from the Swiss Federal Institute of 
Technology in Lausanne. Till 1990 he has been working for $\mathrm{BBC} / \mathrm{ABB}$ in the field of large electrical machines, first as R\&D engineer and later as head of the technical department for hydro- and Diesel-generators. Since 1990 he is full professor at the Federal Institute of technology and director of the laboratory for electrical machines. He is also consultant for different international electrical machines manufacturers and utilities.

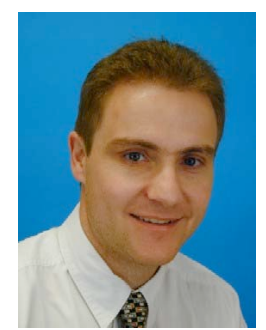

Alain Sapin received his master degree in 1991 and his Ph.D. degree in 1995 from the Swiss Federal Institute of Technology. He has been working from 1996 to 1998 as R\&D engineer in the field of Medium Voltage Adjustable Speed Drives by ABB Industrie AG, Turgi, Switzerland. In 1998, he has been working in the field of SVC by ABB ETI (Electric Technology Institute) in Raleigh, North Carolina, USA. In 1999. Between 1999 and 2001, he was Senior Lecturer at the Swiss Federal Institute of Technology. He is presently Power Production Manager at EEF Company, Switzerland.

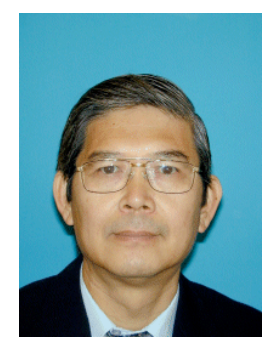

Mai Tu Xuan received his master degree in 1970 and his Ph.D. degree in 1977 from the Swiss Federal Institute of Technology in Lausanne. Since many years he is senior researcher and lecturer at the Laboratory for Electrical Machines of EPFL. His main fields of activities concern machine modeling, optimization and testing, parameters identification,measurement techniques and field calculations.

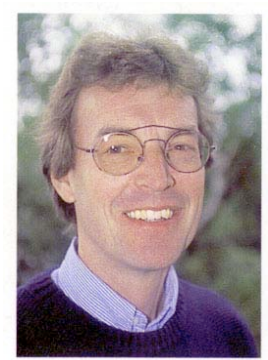

Roland Wetter received his electrical engineer diploma degree in 1977 from the Swiss University of Applied Sciences of Yverdon. In 1978 he joined the Swiss Federal Institute of Technology (EPFL). From 1978 till 1991 he has been working on different fields of activity: study, optimization and test of linear or rotating step motor drive systems, development of didactical equipments for teaching in electromechanics. Since 1991 he is responsible for measurement techniques and data acquisition in the Laboratory of Electrical Machines at EPFL. His main interests concern railway drive systems, energy conversion and savings.

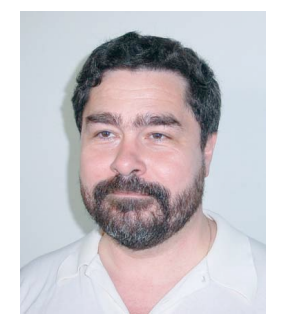

Peter Burmeister (M'93) received the M.S. degree from Swiss Federal Institute of Technology Zurich, Switzerland, in 1979. He has a wide experience in the design and application of large static frequency converters and static Var compensators. He is a Senior System Design 